\title{
Assessment of a Scoring System to Predict Difficult Laparoscopic Cholecystectomy
}

\author{
Prem R Sigdel, Nirajan Subedi, Suman Phuyal, Ashik Pokharel, Bikal Ghimire, Yogendra P Singh \\ Department of GI and General Surgery, Maharajgunj Medical Campus, Tribhuvan University Teaching Hospital, \\ Kathmandu, Nepal
}

\section{Corresponding author:}

\section{Prem R Sigdel, MBBS, MS}

Department of Gl and General Surgery, Maharajgunj Medical Campus, Tribhuvan University Teaching Hospital, Kathmandu, Nepal

Email:prem.sigdel7@gmail.com

Submitted : Mar 19, 2020

Accepted : Oct 29, 2020

\begin{abstract}
Introduction

Laparoscopic cholecystectomy (LC) has become the procedure of choice for management of symptomatic gallstone disease. It would be useful to have some reliable predictive factors for conversion in LC. Our aim is to predict difficult laparoscopic cholecystectomy preoperatively by using a scoring system.
\end{abstract}

\section{Methods}

A total of 136 patients were included. The parameters considered for this study were old age, male sex, history of hospitalization, obesity, abdominal surgery scar, palpable gall bladder, gall bladder wall thickness, pericholecystic collection and impacted stone.

\section{Results}

Among 136 cases, $70.6 \%$ were easy, $24.3 \%$ were difficult and $5.1 \%$ were very difficult intraoperatively. The factors like age $>50$ years, history of hospitalization for acute cholecystitis, previous abdominal surgery, palpable gall bladder, wall thickness $>4 \mathrm{~mm}$ and impacted stone were found statistically significant in predicting difficult LC. The preoperative scoring is statistically and clinically a good test for predicting the difficult LC (area under the curve $=0.824$ ) with sensitivity of the test being $82.3 \%$ and specificity $72.7 \%$. Conversion rate was $3.67 \%$.

\section{Conclusion}

The factors like age $>50$ years, history of hospitalization for acute cholecystitis, previous abdominal surgery, palpable gall bladder, wall thickness $>4 \mathrm{~mm}$ and impacted stone are the preoperative predictors of difficult LC.

\section{Keywords}

Cholecystitis, difficult, laparoscopic cholecystectomy, open cholecystectomy, symptomatic gall stone disease 


\section{INTRODUCTION}

aparoscopic cholecystectomy (LC) is gold standard for management of symptomatic gallstone disease. Advantages of laparoscopic cholecystectomy include reduced hospitalization, decreased morbidity, short recovery time, and better cosmesis. However, compared with open cholecystectomy, the incidence of injuries to the bile duct seems to be increased. ${ }^{1}$ Approximately, $2-15 \%$ of attempted LC has to be converted to an open procedure. ${ }^{2}$ This conversion should neither be considered as a failure nor a complication, but an attempt to avoid complications.

A reliable predictive score for conversion in $L C$ would help inform the patients regarding the possibility of complications and conversion to the open procedure and would help them to be better prepared socially and economically. Patients with a high predicted risk of conversion could be operated on either by or under direct supervision of a experienced surgeon. Various history, clinical and ultrasonological parameters are the predictors of difficult laparoscopic cholecystectomy.

\section{METHODS}

It is a prospective observational study. This study was conducted in Department of GI and General Surgery, Tribhuvan University Teaching Hospital (TUTH), Institute of Medicine. Ethical clearance was obtained from the Institutional Review Committee. Duration of the study was one year. All patients with symptomatic cholelithiasis who underwent laparoscopic cholecystectomy from March 2016 to November 2016 were included in the study after prior informed consent.

A preoperative score was given to every patient after workup in OPD, on the basis of history, clinical examination and sonological findings (Table 1). Gall bladder was defined as distended if the transverse diameter was $>5 \mathrm{~cm}^{3}$ Gall bladder wall $\geq 4 \mathrm{~mm}$ was considered thickened gall bladder. ${ }^{4}$ The scoring system used was of Randhawa and Pujahari. ${ }^{5}$ The scores were added up to get a total score and the patients were divided into categories of risks based on the total score. Score upto 5 was defined as easy, 6-10 as difficult and 11-15 as very difficult.

Operations were conducted under general anaesthesia. LC performed by different competent surgeon (>50 independent LC) was included in this study. Pneumoperitoneum created using Hasson's method. Surgery was done using $\mathrm{CO}_{2}$ pneumoperitoneum with 10 to $12 \mathrm{mmHg}$ pressure. Duration of time is the time taken from skin incision till last port closure. Intra operative events like duration of surgery, bile/stone spillage, and injury to duct/artery were recorded. Laparoscopic cholecystectomy requiring 60-120 minutes and/
Table 1. Patient factors used for scoring

\begin{tabular}{|c|c|c|}
\hline Factors & Score & $\begin{array}{l}\text { Maximum } \\
\text { Score }\end{array}$ \\
\hline \multicolumn{3}{|l|}{ History } \\
\hline Age & & 1 \\
\hline$\leq 50$ year & 0 & \\
\hline$>50$ year & 1 & \\
\hline Sex & & 1 \\
\hline Male & 1 & \\
\hline Female & 0 & \\
\hline $\begin{array}{l}\text { History of hospitalization } \\
\text { for acute cholecystitis }\end{array}$ & & 4 \\
\hline Yes & 4 & \\
\hline No & 0 & \\
\hline \multicolumn{3}{|l|}{ Clinical parameters } \\
\hline $\mathrm{BMI}$ & & 2 \\
\hline$<25$ & 0 & \\
\hline $25-27.5$ & 1 & \\
\hline$>27.5$ & 2 & \\
\hline Abdominal scar & & 2 \\
\hline No & 0 & \\
\hline Infraumbilical & 1 & \\
\hline Supraumbilical & 2 & \\
\hline Palpable gall bladder & & 1 \\
\hline Yes & 1 & \\
\hline No & 0 & \\
\hline \multicolumn{3}{|l|}{ Abdominal sonography } \\
\hline GB wall thickness & & 2 \\
\hline Thin $<4 \mathrm{~mm}$ & 0 & \\
\hline Thick $\geq 4$ mm & 2 & \\
\hline Pericholecystic collection & & 1 \\
\hline No & 0 & \\
\hline Yes & 1 & \\
\hline Impacted stone & & 1 \\
\hline No & 0 & \\
\hline Yes & 1 & \\
\hline
\end{tabular}

or bile leakage and/or injury to duct was labeled difficult. Laparoscopic cholecystectomy requiring $>120$ minutes or conversion to open were labeled as very difficult cases. Data were collected in preformed performa. All categorical data were analyzed using Chi-square test and Fisher's exact test. Delay due to technical reasons were excluded from the study.

Statistical analyses were performed using IBM SPSS 20.0 (IBM Inc., New York, NY). In the descriptive statistics Microsoft word and Excel was used to generate diagram, graphs and tables etc. Descriptive statistics of quantitative data was presented as mean and standard deviation. In the inferential statistics, to find the significant association of findings of preoperative score with intra-operative outcome, Univariate analysis was done with Chi- square test/Fisher exact test. Area under ROC curve has been used to find the 
Table 2. preoperative score and the outcome

\begin{tabular}{|c|c|c|c|c|c|}
\hline \multirow{2}{*}{$\begin{array}{l}\text { Preoperative difficulty } \\
\text { prediction/score }\end{array}$} & \multirow[b]{2}{*}{ Number } & \multicolumn{3}{|c|}{ Intraoperative difficulty level } & \multirow[b]{2}{*}{$p$-value } \\
\hline & & $\begin{array}{c}\text { Easy } \\
\text { no. (\%) }\end{array}$ & $\begin{array}{l}\text { Difficult } \\
\text { no. (\%) }\end{array}$ & $\begin{array}{l}\text { Very difficult } \\
\text { no (\%) }\end{array}$ & \\
\hline Easy $(0-5)$ & $120(88.2)$ & $94(69.11)$ & $22(16.17)$ & $4(2.94)$ & $0.006 * * @$ \\
\hline Difficult (6-10) & $16(11.8)$ & $2(1.47)$ & $11(8.08)$ & $3(2.20)$ & \\
\hline Very difficult (11-15) & - & - & - & - & \\
\hline Total & 136 & $96(70.6)$ & $33(24.26)$ & $7(5.1)$ & \\
\hline
\end{tabular}

@- Fisher's exact test

Table 3. Patient factors used for scoring

\begin{tabular}{|c|c|c|c|c|c|}
\hline \multirow{2}{*}{ Factors } & \multirow{2}{*}{ Cases } & \multicolumn{3}{|c|}{ Intraoperative difficulty level n(\%) } & \multirow{2}{*}{$\mathrm{p}$-value } \\
\hline & & Easy & Difficult & Very difficult & \\
\hline \multicolumn{6}{|l|}{ History } \\
\hline \multicolumn{6}{|l|}{ Age } \\
\hline$\leq 50$ year & $90(66.2 \%)$ & $69(71.90)$ & $18(54.50)$ & 3 & 0.041 \\
\hline$>50$ year & 46 (33.8) & $27(28.10)$ & $15(45.5)$ & 4 & \\
\hline \multicolumn{6}{|l|}{ Sex } \\
\hline Male & $34(25 \%)$ & $22(22.90)$ & $9(27.30)$ & 3 & 0.613 \\
\hline Female & $102(75 \%)$ & $74(77.10)$ & $24(72.70)$ & 4 & \\
\hline \multicolumn{6}{|c|}{$\begin{array}{l}\text { History of hospitalization } \\
\text { for acute cholecystitis }\end{array}$} \\
\hline Yes & $17(12.5)$ & $2(2.10)$ & $11(33.30)$ & 4 & $<0.001 * * @$ \\
\hline No & $119(87.5)$ & 94 (97.9) & $22(66.70)$ & 3 & \\
\hline \multicolumn{6}{|l|}{ Clinical parameters } \\
\hline \multicolumn{6}{|l|}{$\mathrm{BMI}$} \\
\hline$<25$ & $75(55.1 \%)$ & $50(52.10)$ & $22(66.70)$ & 3 & 0.334 \\
\hline $25-27.5$ & $26(19.2 \%)$ & $19(19.80)$ & $4(12.10)$ & 3 & \\
\hline$>27.5$ & $35(25.7 \%)$ & $27(28.10)$ & $7(21.20)$ & 1 & \\
\hline \multicolumn{6}{|l|}{ Abdominal scar } \\
\hline No & $108(79.4 \%)$ & $86(89.60)$ & $19(57.60)$ & 3 & $<0.001 * *$ \\
\hline Infraumbilical & $22(16.2 \%)$ & $10(10.40)$ & $10(30.3)$ & 2 & \\
\hline Supraumbilical & $6(4.4 \%)$ & - & $4(12.1)$ & 2 & \\
\hline \multicolumn{6}{|c|}{ Palpable gall bladder } \\
\hline Yes & $3(2.2 \%)$ & - & $3(9.10)$ & 0 & $<0.016 * @$ \\
\hline No & $133(97.8 \%)$ & $96(100)$ & $30(90.10)$ & 7 & \\
\hline \multicolumn{6}{|c|}{ Abdominal sonography } \\
\hline \multicolumn{6}{|c|}{ GB wall thickness } \\
\hline Thin $<4 \mathrm{~mm}$ & $121(88.97 \%)$ & $94(97.90)$ & $21(63.60)$ & 6 & $<0.001 * * @$ \\
\hline Thick $\geq 4$ mm & $15(11.03 \%)$ & $2(2.10)$ & $12(36.40)$ & 1 & \\
\hline \multicolumn{6}{|c|}{ Pericholecystic collection } \\
\hline No & $135(99.3 \%)$ & $96(100)$ & 32 (97) & 7 & $0.047 * @$ \\
\hline Yes & $1(0.7 \%)$ & - & $1(3)$ & 0 & \\
\hline \multicolumn{6}{|l|}{ Impacted stone } \\
\hline No & $15(11 \%)$ & $1(1)$ & $11(33.3)$ & 3 & $<0.001 * @$ \\
\hline Yes & 121 (89\%) & 95 (99) & 22 (66.70) & 4 & \\
\hline
\end{tabular}

Diagnostic and predictive value of preoperative score for predicting the preoperative outcome based on easy and difficult binary outcome. If $p<0.001$ then the variables was called highly significant, if $p \leq 0.01$ then strongly significant and $0.01<p \leq 0.05$, then the variables was called moderately significant.

\section{RESULTS}

A total of 136 patients were included in the study with distribution of parameters in Table 2. The mean age of the study cases was $45.33 \pm 2.11$ years with the minimum age being 15 years and the maximum 


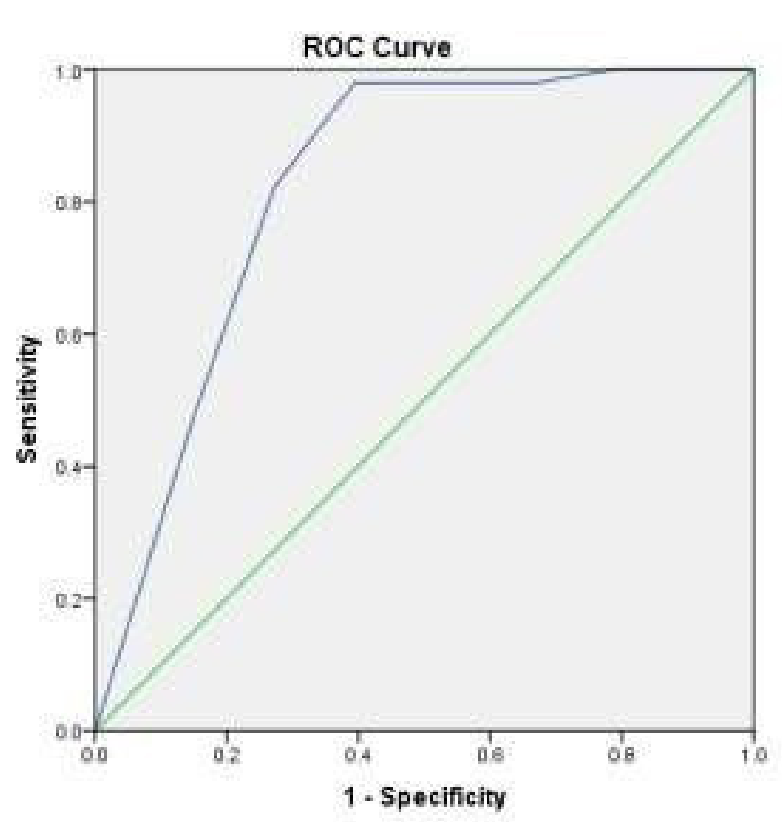

Diagonal segments ate produced by ties

Fig 1. ROC curve and its area under curve for predicting the difficult $L C$ based on preoperative scores

being 80 years. Hypertension was the most common comorbidity among the patients followed by diabetes mellitus.

Among 136 cases, 120 cases were predicted to be easy, 16 cases were predicted to be difficult and none of the cases were predicted to be very difficult (Table 3). Intraoperatively, 96 cases were easy, 33 cases were difficult and 7 cases were very difficult (Table 4). Among 120 cases predicted to be easy, 94 were actually easy intraoperatively and among 16 cases that were predicted to be difficult, 14 cases came to be difficult intraoperatively.

The factors like age $>50$ years, history of hospitalization, previous abdominal surgery, palpable gall bladder, wall thickness and impacted stone were found statistically significant in predicting difficult LC (Table 4). The predictive association of the preoperative score with intraoperative outcome was statistically significant with $p$-value of 0.006 (Table 5). Area under the receiver operating characteristic (ROC) curve is 0.824 with $95 \%$ confidence interval (Figure 1).

The preoperative scoring is statistically and clinically a good test for predicting the difficult LC (area under ROC $=0.824)$ with sensitivity of the test being $82.3 \%$ and specificity $72.7 \%$.

\section{DISCUSSION}

Laparoscopic cholecystectomy is one of the most commonly performed surgeries. Initially, the complication rate with LC was high but with technological advancement and increase in the expertise, it has now reached a remarkably low level at $2.0-6.0 \%{ }^{6}$

The mean operative time in our study was 63 minutes that was comparable with other studies. Conversion rate of $7-35 \%$ has been reported in literature. ${ }^{7}$ In our study, the conversion rate was $3.67 \%(5 / 136)$. Among the five cases that were converted to open, four cases had previous history of cholecystitis. Intraoperatively, dense adhesion was present in between the bowel, peritoneum and the gall bladder. The fifth case had history of gastrectomy. Intraoperatively, transverse colon was adhered to anterior abdominal wall. In a study of 204 patients with difficult situation cholecystitis in 2015, so the conversion rate was slightly high $(7.35 \%) .{ }^{8}$ Almost all LC are done in elective basis in our hospital. This might be the reason for slightly lower rate of conversion to open cholecystectomy in our study. Another reason might be more experienced surgeons tending to operate on cases considered to be difficult. There was no major biliary injury in our patients.

Old age (age $>50$ years) has been found to be a significant risk factor for difficult laparoscopic cholecystectomy with increased conversion rate in many studies.., 10 In our study also, it is found to be statistically significant. Male sex makes surgery difficult as being reported in studies. ${ }^{10,11}$ Our study did not show male sex to be significant factor for difficulty. Small study group and an unequal distribution of patients on the basis of sex could have altered the results in our series.

Patient, who require hospitalization for repeated attacks of acute cholecystitis may produce a dense adhesions at calot's triangle and gall bladder fossa. This study found a strong correlation between previous hospitalization for laparoscopic cholecystectomy and difficult LC. Port placement in obese patient takes longer time due to the thick abdominal wall. Dissection at the Calot's triangle is also technically difficult due to the obscure anatomy because of excessive intraperitoneal fat and difficulty in the manipulation of instruments through an excessively thick abdominal wall. ${ }^{12}$ In our study, we found no correlation between $\mathrm{BMI}$ and difficult level of surgery.

After previous upper or lower abdominal surgery there may be adhesions present between viscera or omentum and abdominal wall. Lee et al found previous upper abdominal surgery as independent risk factor for difficult LC. ${ }^{9}$ In our study only 22 patients had infra-umbilical scar and 6 supraumbilical scar. ${ }^{13}$ Our study found previous abdominal surgery to be a significant factor for prediction of difficult laparoscopic cholecystectomy.

Palpable gall bladder is a clinical finding seen in patients with distended gall bladder due to mucocele or empyema etc. In distended gall bladder it is difficult to catch hold of the fundus of 
$\mathrm{GB}$ and hence aspiration of the contents of $\mathrm{GB}$ is often required. It is cumbersome, time consuming and also there is chance of spillage of contents into the peritoneal cavity. In our study, palpable gall bladder was the significant variable for predicting difficult laparoscopic cholecystectomy.

Increased GB wall thickness is associated with difficult dissection of the GB from its bed. Thick gall bladder is related to the inflammation and fibrosis that follows attacks of cholecystitis and thus may reflect difficulty in delineation of the anatomy during surgery and difficult to remove gall bladder. The thickness of gall bladder associated with difficulty varies from study to study. It was $3 \mathrm{~mm}^{12-14}$ or $4 \mathrm{~mm} .^{8}$ Critical gall bladder wall thickness was taken as $4 \mathrm{~mm}$ in our study. Thickened gall bladder wall was found in 15 patients and was a significant predictor for difficulty.

Pericholecystic fluid is an ultrasonographic finding of acute cholecystitis. Saber et al found significant correlation between the pericholecystic collection and difficult LC. ${ }^{8}$ This was found to be a significant factor in our study (p-value 0.047). However we had only one patient with pericholecystic collection. We have the practice of interval cholecystectomy after at least of 6 weeks after the attack of acute cholecystitis.

Several studies have evaluated the risk factors for conversion from LC to OC. Schrenk et al. assessed the preoperative and perioperative risk factors of conversion from LC to Open cholecystectomy. They found significant risk factors in 56 (4.3\%) patients who required conversion to OC. The risk factors being rigidity in the right upper quadrant, increased thickness of the gallbladder wall, dense adhesions, and the presence of acute cholecystitis. ${ }^{8}$ Randhawa et al proposed a 15-point scoring system from history, clinical, sonological findings. Score up to 5 predicted easy, 6-10 difficult and $>10$ are very difficult. They concluded that BMI > 27.5 ( $p<$ $0.010)$, previous hospitalization $(p<0.001)$, palpable GB ( $p<0.01$ ) US-Thick-walled GB ( $p<0.038$ ) were significant in predicting difficult LC. ${ }^{5}$ We assessed the scoring system proposed by Randhawa et al for prediction of difficult LC in our study. Sensitivity and specificity of the scoring system at score 5 for prediction of easy or difficult laparoscopic cholecystectomy are $83 \%$ and $72 \%$ respectively. Area under ROC curve is 0.82. Prediction comes true in $75 \%$ for easy and $82 \%$ for difficult. Thus, the scoring system given by Randhawa can be used for predicting the difficult $L C$ cases.

There are few limitations of the study. The time requirement for the procedure depends on the surgical expertise of the operating surgeon, that varies between one surgeon to another. In our study, there were multiple surgeons. Cases considered to be difficult such as recurrent cholecystitis were usually operated by more experienced surgeons which might have added to the selection bias. Referral bias of difficult cases to the tertiary center may have altered the results.

\section{CONCLUSION}

The factors like age more than 50 years, history of hospitalization for acute cholecystitis, previous abdominal surgery, palpable gall bladder, wall thickness $(>4 \mathrm{~mm})$, pericholecystic collection and impacted stones are the risk factors for difficult LC. The preoperative scoring system can accurately predict the difficult LC.

\section{CONFLICT OF INTEREST}

None declared.

\section{REFERENCES}

1. Strasberg SM, Hertl M, Soper NJ. An analysis of the problem of biliary injury during laparoscopic cholecystectomy. J Am Coll Surg, 1995. 180(1): p. 101-25.

2. Alponat A, Kum CK, Koh BC, et al., Predictive factors for conversion of laparoscopic cholecystectomy. World J Surg, 1997. 21(6): p. 629-33.

3. Daradkeh SS, Suwan Z, Abu-Khalaf M.Preoperative ultrasonography and prediction of technical difficulties during laparoscopic cholecystectomy. World J Surg, 1998. 22(1): p. 75-7.

4. Santambrogio R, Montorsi M, Bianchi P, et al., Technical difficulties and complications during laparoscopic cholecystectomy: predictive use of preoperative ultrasonography. World J Surg, 1996. 20(8): p. 978-81; discussion 981-2.

5. Randhawa JS, Pujahari AK. Pujahari, Preoperative prediction of difficult lap chole: a scoring method. Indian J Surg, 2009. 71(4): p. 198-201.

6. Gadacz TR. Update on laparoscopic cholecystectomy, including a clinical pathway. Surg Clin North Am, 2000. 80(4): p. 1127-49.

7. Khan IA, El-Tinay OE. Laparoscopic cholecystectomy for acute cholecystitis. Can preoperative factors predict conversion? Saudi Med J, 2004. 25(3): p. 299-302.

8. Saber A, Abu-Elela ST, Shaalan KM, et al. Preoperative Prediction of the Difficulty of Laparoscopic Cholecystectomy. Journal of Surgery and Surgical Research, 2015. 1(1): p. 015-018.

9. Lee NW, Collins J, Britt R, et al. Evaluation of preoperative risk factors for converting laparoscopic to open cholecystectomy. Am Surg, 2012. 78(8): p. 831-3.

10. Hussain A. Difficult laparoscopic cholecystectomy: current evidence and strategies of management. Surg Laparosc Endosc Percutan Tech, 2011. 21(4): p. 211-7.

11. Al-Mulhim AA. Male gender is not a risk factor for the outcome of laparoscopic cholecystectomy: a single surgeon experience. Saudi J Gastroenterol. 2008;14(2):73-79.

12. Fried GM, Barkun JS, Sigman HH, et al., Factors determining conversion to laparotomy in patients undergoing laparoscopic cholecystectomy. Am J Surg, 1994;167(1):35-9; discussion 39-41.

13. Nachnani J, Supe A. Pre-operative prediction of difficult laparoscopic cholecystectomy using clinical and ultrasonographic parameters. Indian J Gastroenterol, 2005. 24(1): p. 16-8.

14. Majeski J. Significance of preoperative ultrasound measurement of gallbladder wall thickness. Am Surg, 2007. 73(9): p. 926-9. 